\title{
Single atom catalyst by atomic layer deposition technique
}

\author{
Niancai Cheng a,b, Xueliang (Andy) Sun a,* \\ a Department of Mechanical and Materials Engineering, University of Western Ontario, London, ON N6A 5B9, Canada \\ ${ }^{\mathrm{b}}$ College of Materials Science and Engineering, Fuzhou University, Fuzhou 350108, Fujian, China
}

\section{A R T I C L E I N F O}

\section{Article history:}

Received 6 July 2017

Accepted 14 August 2017

Published 5 September 2017

\section{Keywords:}

Single-atom

Atomic layer deposition

Catalysis

Noble catalyst

Mechanism

\section{A B S T R A C T}

Noble single-atom catalysts have rapidly been attracting attention due to their unique catalytic properties and maximized utilization. Atomic layer deposition (ALD) is an emerging powerful technique for large-scale synthesis of stable single atom. In this review, we summarize recent developments of single atom synthesized by ALD as well as explore future research direction and trends.

(C) 2017, Dalian Institute of Chemical Physics, Chinese Academy of Sciences. Published by Elsevier B.V. All rights reserved.

\section{Introduction}

Noble metal catalysts play a very important role in a wide range of industrial applications. Noble catalysts, such as Pt, Pd, $\mathrm{Ru}, \mathrm{Rh}$, and Ir have been widely used in chemical transformation, energy conversion, and environmental protection. However, owing to the high price and low natural abundance of such noble metals, the increasing need for these elements cannot be met. One strategy toward maximizing the catalytic use of nobel metals is to reduce the catalyst size in order to increase the active surface area. Downsizing noble metal catalyst particle size to nanometers, clusters or even single atoms, is an effective strategy to significantly increase catalytic activity and enhance efficiency. Recently, noble single-atom catalysts (SAC) have attracted rapidly increasing attention due to their unique catalytic properties and maximized utilization leading to reduced cost.

Single-atom catalysts have shown unexpectedly high specific activity, with a significant reduction in usage for $\mathrm{CO}$ oxidation [1-3], water-gas shift reaction [4-6], fuel cells [7,8] and hydro- genation reactions [9-11]. For examples, single-atom Pt supported on $\mathrm{FeO}_{x}$ substrates demonstrated a 2-3 times higher activity than its cluster counterpart. Furthermore, this unique combination displayed excellent stability toward CO oxidation and preferential oxidation of $\mathrm{CO}$ in $\mathrm{H}_{2}$ [1]. The remarkable performance of single atom Pt supported on $\mathrm{FeO}_{x}$ stems from the unique electronic structure of partially vacant $5 d$ orbitals of the positively charged and high-valent Pt atoms, as confirmed by X-ray absorption near edge structure (XANES) and density functional theory (DFT) analysis. Single Pd atom catalysts were also achieved by the anchoring of Pd atoms into the cavities of mesoporous polymeric graphitic carbon nitride [10]. Single Pd atoms showed high activity and product selectivity for the flow hydrogenation of alkynes and nitroarenes compared with supported Pd nanoparticles. The Pd single atoms surpassed the activity of conventional heterogeneous nanoparticle catalysts and maintained an outstanding degree of product selectivity (> $90 \%)$. Single atom catalysts are a promising new generation of water gas shift (WGS) catalysts for maximizing their activity and catalytic efficiency [12-14] An isolated $\mathrm{Au}$ species an-

\footnotetext{
* Corresponding author. E-mail: xsun@eng.uwo.ca DOI: 10.1016/S1872-2067(17)62903-6 | http://www.sciencedirect.com/science/journal/18722067 | Chin. J. Catal., Vol. 38, No. 9, September 2017
} 
chored through -0 ligands to different supports such as ceria $[15,16]$ and titania [17] have been successfully prepared for WGS reaction. The atomically dispersed gold species, with surrounding extra surface-OH groups, $\left(\mathrm{Au}-(\mathrm{OH})_{x}\right)$ have been identified as the active sites for the WGS reaction.

Single atom catalysts were also designed for oxygen reduction reaction (ORR). The inherently sluggish kinetics of the ORR and instability of platinum at the cathode are the foremost challenges for widespread commercialization of polymer electrolyte fuel cells (PEMFCs) $[18,19]$. Pt is the high cost and scarcity. It is extremely desirable to develop highly active, stable and inexpensive ORR electrocatalysts. When Pt nanoparticle downsized to single atoms, the Pt single atoms does not show good ORR activity because the ORR need platinum ensemble sites in acid media [8]. The similar results were also obtained on the single Pt atoms anchored in sulfur-doped ZTC (HSC). Single Pt atom catalysts do not follow a conventional four electron pathway producing $\mathrm{H}_{2} \mathrm{O}$, but selectively produces $\mathrm{H}_{2} \mathrm{O}_{2}$ without significant degradation of the activity. However, the single-atom catalyst of single niobium atoms trapped within the graphitic layers showed a good ORR activity in alkaline solution [20]. The advanced structure of trapped single atom not only enhance the overall conductivity for accelerating the exchange of ions and electrons, but also suppress the chemical/thermal coarsening of the active particles. Experimental and theoretical studies revealed that the single niobium atoms produced a redistribution of $d$-band electrons, thus becoming extremely active for $\mathrm{O}_{2}$ adsorption and dissociation, and exhibiting high stability. Recently, Sun et al. [21] reported a cost-effective, high performance and durable carbon-supported Pt SAC for highly efficient 4e ORR in acid media. DFT calculations indicate that the single-pyridinic-nitrogen(P-N) -atom-anchored single $\mathrm{Pt}$ atom centers are the main active sites, which are highly active for ORR.

However, upon downsizing noble metal catalysts, to clusters or single-metal atoms, structural stability is compromised, resulting in a natural tendency for metal atoms to diffuse and agglomerate, causing larger particles to form. In practical applications, it is required that the single atom and cluster catalysts have an activity on the scale of (if not higher than) conventional Pt nanoparticles, while also maintaining their stability with cycling in order to prevent particle growth with time. This suggests that not only must single atoms be successfully prepared, but they must also exhibit high activity and high stability. In order to solve the challenges facing single atom catalysts, we first need to explore fabrication methods employed for the preparation of stable single atom catalyst with high loading. Many methods such as co-precipitation method [22-24], impregnation method [2,8,25,26], pyrolysis synthesis $[27,28]$, mass-selected soft-landing method $[29,30]$ and atomic layer deposition (ALD) [31,32] have been developed to fabricate single atom catalysts. In this review, we will focus on how to design highly stable and active single atom catalysts by atomic layer deposition (ALD). We will introduce the mechanism of ALD for synthesis of single atom catalysts. We also summarize state-of-the-art progresses on single atom catalysts. This will provide a useful platform upon which to design in- dustrial catalyst.

\section{The mechanism of ALD for single atom}

ALD is gaining increasing attention as a technique for deposition of noble metals and metal oxides due to its ability in preparing uniform and conformal thin films, as well as the deposition of uniformly distributed particles ranging from single atoms, to sub-nanometer clusters, to NPs in high-aspect-ratio structures and porous materials [33-37]. Generally, the ALD process includes four steps, as shown in Fig. 1 [38,39]: (1) Exposure to first precursor, (2) purge of the reaction chamber, (3) exposure to second reactant precursor, and (4) a further purge of the reaction chamber. In ALD process, the key character is self-limiting reactions, which makes it possible to precisely control over size or thickness of the deposited materials at the atomic level. In the first half reaction (steps (1) and (2)), the first precursor reacts with all available active sites (functional groups or defect) on the substrate, in which a fraction of ligands of the precursor are partially removed. Then residue of the first precursor and reaction byproducts are purged with an inert gas. In the second half reaction (step (3) and (4)), the reactant precursor reacts with the adsorbed precursor on the substrate to get the target material by removing the remaining ligands of the first precursor. In this reaction, it is very important to regenerate active sites on the surface of deposited materials for the next cycle deposition. The residuals of the second precursor and byproducts are purged with an inert gas and complete the reaction cycle. The desired thickness or size can be achieved by the controlled number of cycles. Based on sequential and self-limiting reactions, ALD is capable of producing a variety of thin films with precise control at the atomic level. However, some deviations from ideal growth, such as nucleation delay or island growth during the initial film growth stage of noble metals ALD, are often observed. The following reasons are responsible for the formation of nanoparticle instead of Pt film: (1) Limited functional groups on the substrate surface. During the initial of ALD process, the precursor first reacts with functional groups on the surface of the substrate

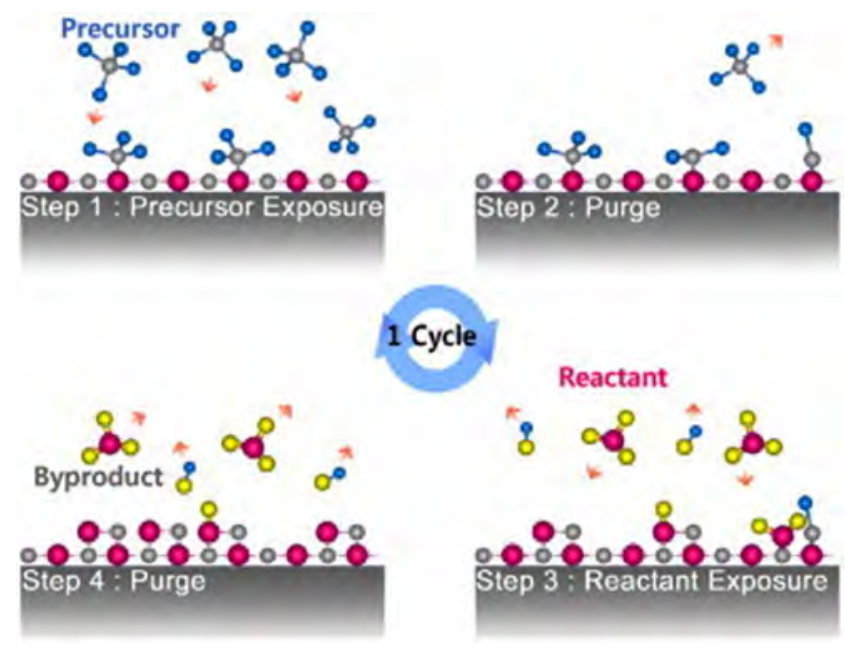

Fig. 1. Schematics showing the growth process of ALD. Reproduced with permission from Ref. [39]. 
followed by the formation of atoms $[18,40]$. However, functional groups are limited on the substrate surface which will lead to formation of nanoparticle instead of film. (2) Difference in surface energy of ALD metal and substrate [38,41]. When the surface energy of the substrate is lower than the free energy of deposited materials, the substrate cannot wetted by the deposited materials which will lead to insufficient adsorption sites and results in an island growth mode. However, a layer-by-layer growth mode is preferred when the reverse is true. Therefore, the substrate with higher surface energy enables the growth of continuous and ultrathin films of lower surface energy metals. The noble metals usually have higher surface energy than the carbon support or metal oxides.

\section{Some examples of ALD single atoms}

Sun's group [31] first reported the practical synthesis of isolated single $\mathrm{Pt}$ atoms anchored to graphene nanosheets (GNS) using the precursor (methylcyclopenta-dienyl) trimethylplatinum ( $\mathrm{MeCpPtMe}_{3}$ ) and $\mathrm{O}_{2}$ counter reactant by the ALD technique. The reaction is hypothesized to occur as follows: Pt-O* $+(\mathrm{MeCp}) \mathrm{Pt}\left(\mathrm{CH}_{3}\right)_{3} \rightarrow\left(\mathrm{CH}_{3}\right)_{2} \mathrm{Pt}(\mathrm{MeCp})+\mathrm{CO}_{2} \uparrow+\mathrm{H}_{2} \mathrm{O} \uparrow$ + fragments

$\left(\mathrm{CH}_{3}\right)_{2} \mathrm{Pt}(\mathrm{MeCp})^{*}+\mathrm{O}_{2} \uparrow \rightarrow$ Pt- $0^{*}+\mathrm{CO}_{2} \uparrow+\mathrm{H}_{2} \mathrm{O} \uparrow+$ fragments $(2)$

After 50 cycles of ALD Pt on GNS, high angle annular dark field STEM (HAADF-STEM) images (Fig. 2(A)) showed, in addition to some Pt NPs, the presence of numerous individual $\mathrm{Pt}$ atoms as well as very small Pt clusters $(<1 \mathrm{~nm})$ consisting of a few atoms. After 100 cycles, the clusters increase in size and form NPs with particle size between 1 and $2 \mathrm{~nm}$. Finally, after 150 cycles, existing clusters and particles from 50 and 100 cycle samples appear even larger and can be grouped in 3 sizes of 1, 2 and $4 \mathrm{~nm}$, respectively. The single Pt atom catalysts have been tested for their methanol oxidation reaction (MOR) activity, and exhibit significantly enhanced catalytic activity (up to 10 times) compared to state-of-the-art commercial Pt/C catalyst. The increased MOR activity for ALD50-Pt/GNS can be attributed to the small catalyst size employed, resulting in increased utilization of Pt atoms. X-ray absorption fine structure (XAFS) analysis revealed that the low-coordination and par-
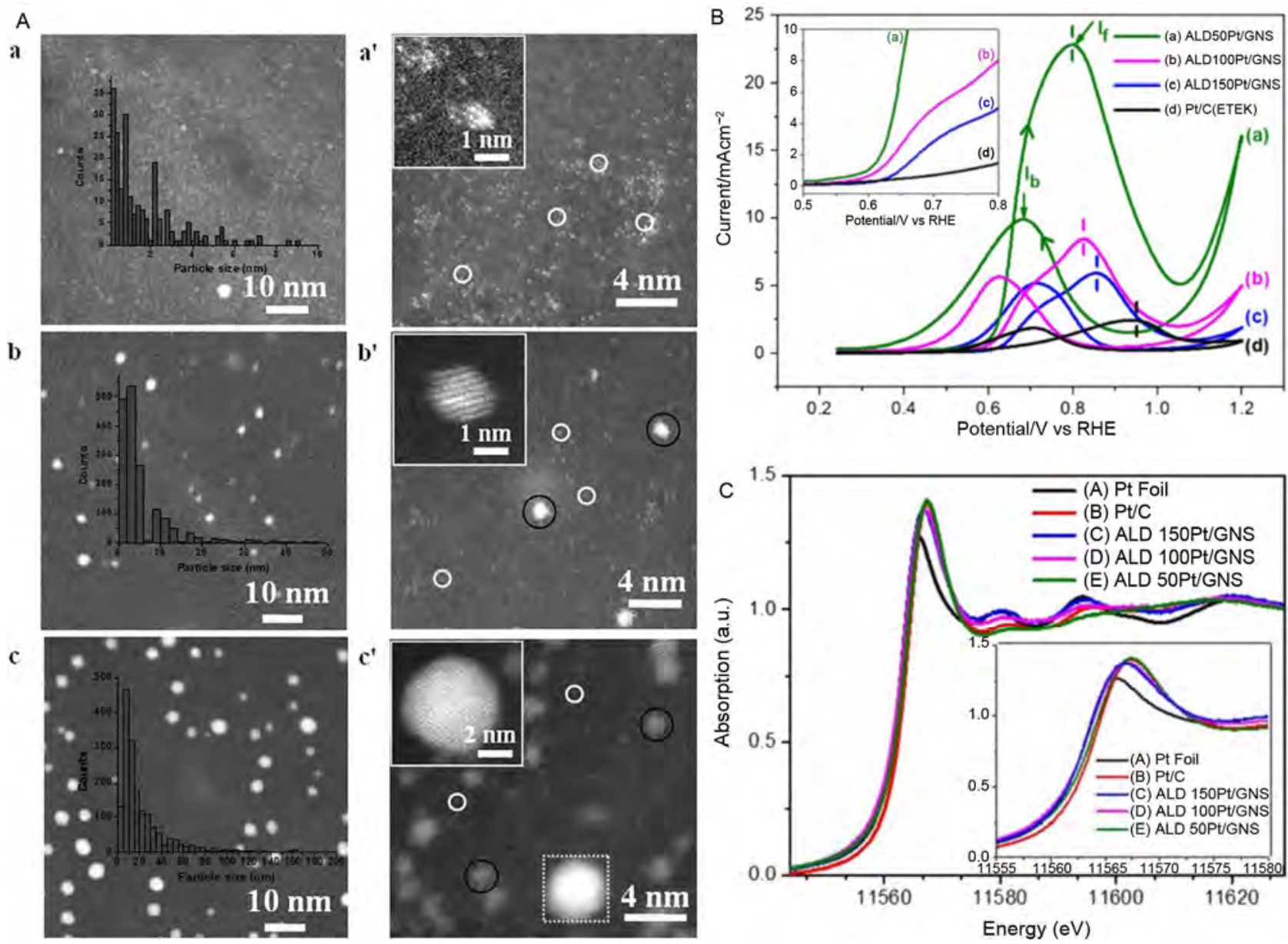

Fig. 2. (A) HAADF-STEM images of Pt/GNS samples. (a,b,c) present the results with 50, 100, and 150 ALD cycles, respectively, and (a',b',c') show the corresponding magnified images. Inset in each figure show the corresponding histogram of Pt on GNS. (B) CVs of methanol oxidation on (a) ALD50Pt/GNS, (b) ALD100Pt/GNS, (c) ALD150Pt/GNS, (d) Pt/C. The inset is the enlarged CV curves at the onset potential region of the methanol oxidation on different catalysts. The methanol oxidation peak current density indicates that ALD50Pt/GNS is 4 and 2.7 times more active than ALD100Pt/GNS and ALD100Pt/GNS, respectively. Most importantly, all ALDPt/GNS catalysts exhibit several times higher activity for MOR than that of Pt/C catalyst. In partticular, ALD50Pt/GNS is over 9.5 times more active than of Pt/C catalyst. (C) The normalized XANES spectra at Pt L3 edge. Inset in $\mathrm{C}$ shows the enlarged spectra at $\mathrm{Pt} \mathrm{L}_{3}$ edge. Reproduced with permission from Ref. [31]. 
tially unoccupied densities of states of $5 d$ orbital of Pt atoms were also responsible for the improved performance.

Pt-based catalysts are generally considered to be the most effective electrocatalysts for the hydrogen evolution reaction (HER) [42,43]. Unfortunately, Pt is expensive and scarce, limiting its commercial potential. The development of active, stable, and inexpensive electrocatalysts for water splitting is a key step in the realization of a hydrogen economy which is based on the use of molecular hydrogen for energy storage. Single cobalt atoms anchored on $\mathrm{N}$-doped graphene has demonstrated excellent catalytic performance toward the HER, making it a promising candidate to replace Pt for water splitting applications [44]. Although single atom cobalt displays promising potential for use in the HER, its activity is still lower than Pt, and is insufficient for industrial application [45]. Recently, Sun's group [32] reported on the practical synthesis of isolated single Pt atoms on N-doped graphene using ALD, as shown in Fig. 3. The single Pt atom catalysts have been investigated for the HER, where they exhibit significantly enhanced catalytic activity (up to 37 times) and high stability in comparison to the state-of-the-art commercial Pt/C catalysts. Through the synchrotron and DFT analyses, it was determined that the interac-
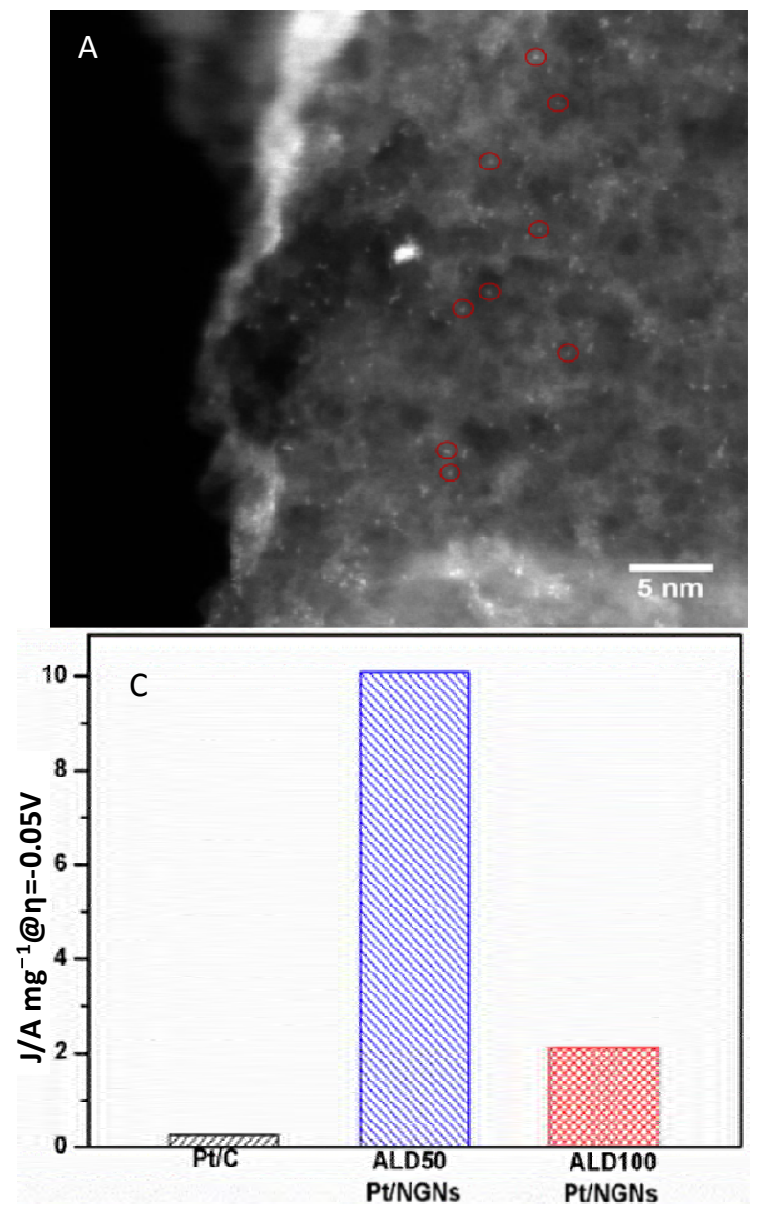

Fig. 3. (A)ADF STEM images of ALDPt/NGNs samples with 50 cycles. (B) The normalized XANES spectra at the Pt L3-edge of the ALDPt/NGNs, Pt/C catalysts and Pt foil. The inset shows the enlarged spectra at the Pt L3-edge. (C) Mass activity at $0.05 \mathrm{~V}$ (versus RHE) of the ALDPt/NGNs and the Pt/C catalysts for the HER. (D) Durability measurement of the ALD50Pt/NGNs. The polarization curves were recorded initially and after 1000 cyclic voltammetry sweeps between +0.4 and $-0.15 \mathrm{~V}$ (versus RHE) at $100 \mathrm{mVs}^{-1}$ in $0.5 \mathrm{M} \mathrm{H}_{2} \mathrm{SO}_{4}$ at a scan rate of $2 \mathrm{mVs}^{-1}$. Reproduced with permission from Ref. [32]. tion between the metal atoms and the support played a vital role in the stabilization of single Pt atom. First-principles calculations showed that the interaction between single Pt atoms and N-dopants was about $5.3 \mathrm{eV}$, which is approximately $3.4 \mathrm{eV}$ larger than the bond strength between Pt atoms and the graphene substrate; thus suggesting that Pt prefers to bind to $\mathrm{N}$-sites. Their work also demonstrates that the remarkable performance of the single Pt atoms arises from their small size and unique electronic structure, originating from the adsorption of single Pt atoms on the N-doped graphene, as confirmed by XANES and DFT analysis.

To achieve single Pd atom, Lu et al. [46] employed a single pulse exposure of Pd(hfac) 2 in order to saturate the surface of graphene (Fig. 4). The single atom Pd catalysts showed remarkable performance in selective hydrogenation of 1,3-Butadiene. In selective hydrogenation of 1,3-butadiene, the single-atom $\mathrm{Pd}_{1} /$ graphene catalyst showed about $100 \%$ butene selectivity at $95 \%$ conversion under mild reaction conditions of $50{ }^{\circ} \mathrm{C}$. More importantly, excellent durability against deactivation via either aggregation of metal atoms or carbonaceous deposits during a total $100 \mathrm{~h}$ of reaction time on stream was achieved. Recently, this group synthesized a single-atom
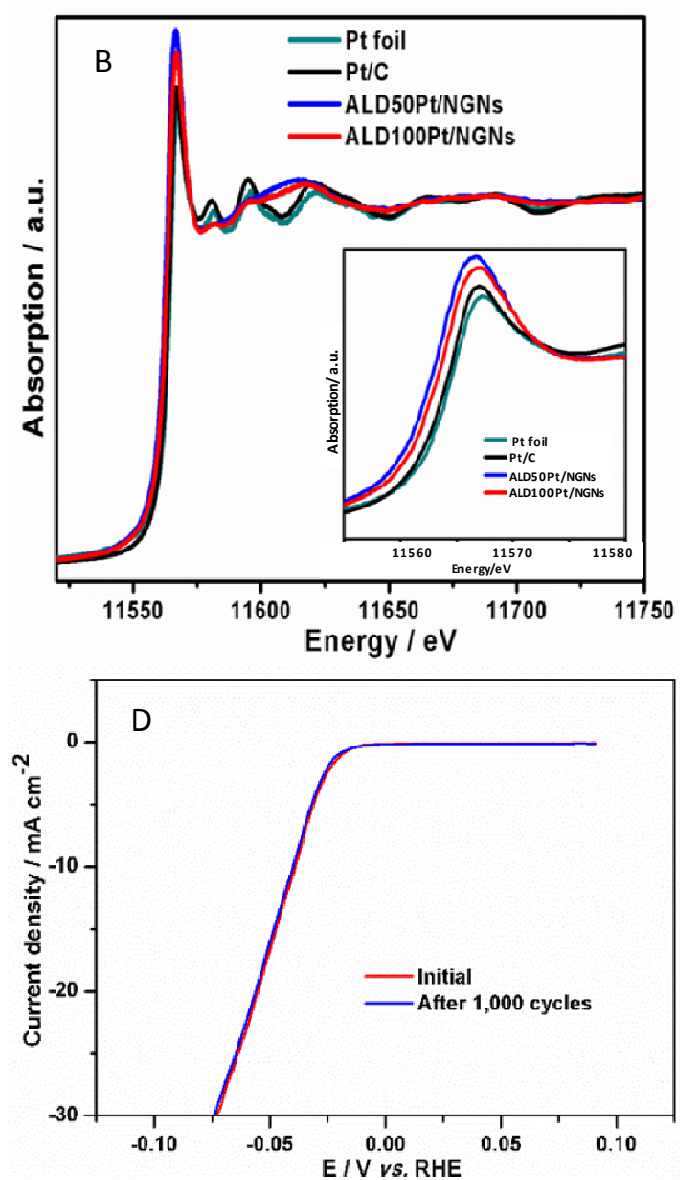

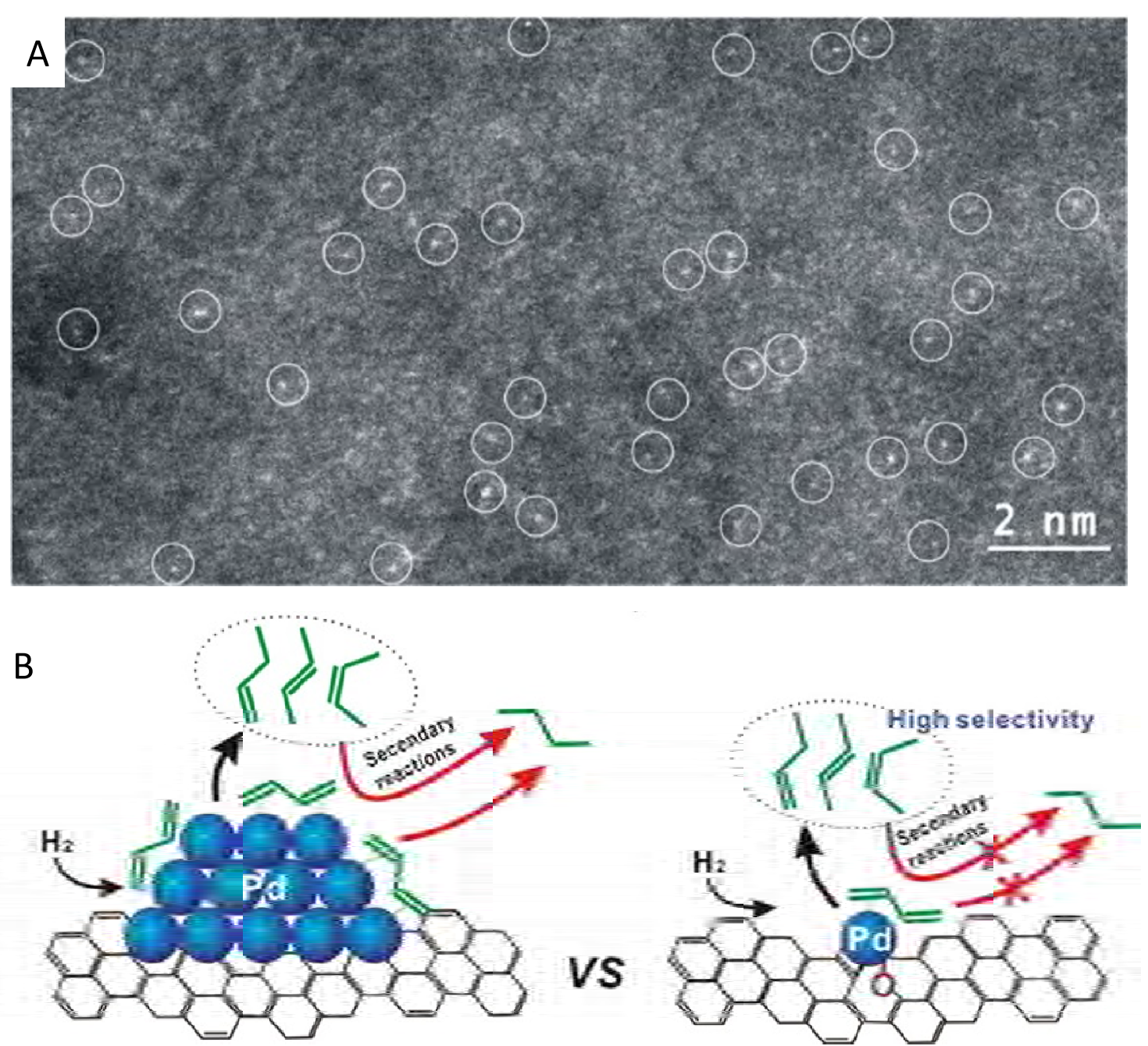

Fig. 4. (A) HAADF-STEM images of Pd1/graphene at high magnifications. (B) Schematic illustration of improvement of butenes selectivity on singleatom Pd1/graphene catalyst. Reproduced with permission from Ref. [46].

$\mathrm{Pt}_{1} / \mathrm{CeO}_{2}$ catalyst using $\mathrm{ALD}$ through a long pulse exposure time (50 s) of $\mathrm{MeCpPtMe}_{3}$ at $150^{\circ} \mathrm{C}$ [47]. Then the ligands were removed in $10 \% \mathrm{O}_{2}$ in $\mathrm{Ar}$ at $200{ }^{\circ} \mathrm{C}$. In $\mathrm{CO}$ oxidation, they found that water showed a remarkable promotion (about $50 \%$ ) of the activity of $\mathrm{Pt}_{1} / \mathrm{CeO}_{2}$ catalyst via a water-mediated Mars-van Krevelen (MvK) mechanism.

Lei et al. [48] demonstrated an approach to stabilize single-atom $\mathrm{Pd}_{1}$ catalysts through ultrathin metal oxide protective coatings prepared by ALD. As shown in Fig. 5, the Pd precursor firstly chemisorbed on the surface of $\mathrm{Al}_{2} \mathrm{O}_{3}$ using Palladium hexafluoroacetylacetonate $\left(\mathrm{Pd}(\mathrm{hfac})_{2}\right)$ by the first half reaction of ALD. Then the ultrathin metal oxide $\left(\mathrm{TiO}_{2}\right)$ coatings were deposited on the substrate by ALD. The $\mathrm{TiO}_{2}$ grew selectively on the substrate and not on the chemisorbing $\mathrm{Pd}(\mathrm{hfac})_{2}$ onto the substrate surface because the remaining hfac ligands prevent $\mathrm{TiO}_{2}$ growth during the metal oxide ALD. The Pd atoms were formed in $\mathrm{TiO}_{2}$ nanocavity by removing the -hfac ligands using formalin (HCHO) in the second half reaction of ALD. The thermal stability of the $\mathrm{Pd}_{1}$ catalysts in the nanocavity thin film structure is significantly enhanced. In situ infrared spectroscopy and Pd K-edge X-ray absorption spectroscopy (XAS) revealed that the $\mathrm{Pd}_{1}$ was anchored on the surface through chlorine sites.

\section{Concluding remarks and future directions}

ALD has been shown to be a powerful tool for large-scale synthesis of stable single atom. The properties of sub-
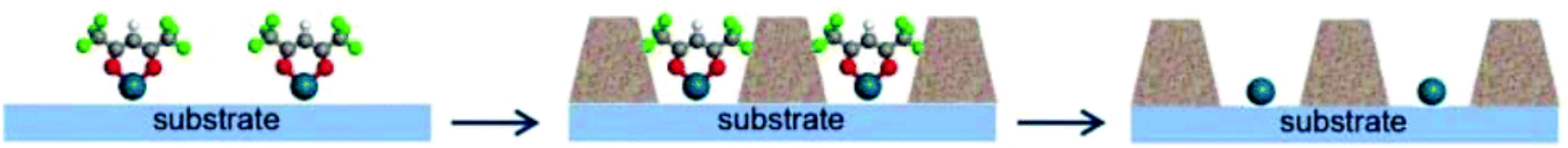

Fig. 5. Schematics of thermally stable $\mathrm{Pd}_{1}$ catalysts synthesized using ALD. (1) Depositing $\mathrm{Pd}(\mathrm{hfac})$ on spherical $\mathrm{Al}_{2} \mathrm{O}_{3}$ substrate, (2) creating nanocavity structure using $\mathrm{TiO}_{2} \mathrm{ALD}$, and (3) removing-hfac ligands using HCHO. Reproduced with permission from Ref. [48]. 
strates/supports are believed to play an important role in formation and stability of SAC synthesized by ALD technique. Compared with other methods such as co-precipitation method, impregnation method and mass-selected soft-landing method, one of important advantages of ALD for single atom synthesis is precise control of the formation of SACs on different structure substrates including 1D, 2D and 3D materials. In addition, ALD can not only synthesize single atom catalysts, but also design novel structure such as nanocavity to stabilize single atom catalysts. It is worth noting that high cost resulting from equipment and precursors are not favorable for large-scale production.

To achieve high loading, stable single atom catalysts, the following future research efforts are proposed:

(1) The increased understanding of ALD mechanisms will play a critical role in design of high loading and stable single atom catalysts on substrates. In particular, further understanding of ALD nucleation and deposition mechanisms, and optimization and control of substrate surface properties are needed.

(2) Development of low cost of ALD precursors is very important for large-scale production. The large scale applications of ALD can also subsequently bring down the precursor cost drastically.

(3) Design of novel structure and surface of the substrates to stabilize single atom catalysts by taking advantage of ALD's features is another important future direction. For example, single atom catalysts can be stabilized in metal oxides nanocavity by selectively ALD.

\section{Acknowledgments}

This work was supported by the Natural Science and Engineering Research Council of Canada (NSERC), the Canada Research Chair Program (CRC) and the University of Western Ontario (UWO). Also, thank Andrew Lushington for editing the manuscript and discussion.

\section{References}

[1] B. T. Qiao, A. Q. Wang, X. F. Yang, L. F. Allard, Z. Jiang, Y. T. Cui, J. Y. Liu, J. Li, T. Zhang, Nat. Chem., 2011, 3, 634-641.

[2] M. Moses-DeBusk, M. Yoon, L. F. Allard, D. R. Mullins, Z. L. Wu, X. F. Yang, G. Veith, G. M. Stocks, C. K. Narula, J. Am. Chem. Soc., 2013, 135, 12634-12645.

[3] B. T. Qiao, J. X. Liang, A. Q. Wang, C. Q. Xu, J. Li, T. Zhang, J. J. Liu, Nano. Res., 2015, 8, 2913-2924.

[4] M. Yang, S. Li, Y. Wang, J. A. Herron, Y. Xu, L. F. Allard, S. Lee, J. Huang, M. Mavrikakis, M. Flytzani-Stephanopoulos, Science, 2014, 346, 1498-1501.

[5] J. Lin, A. Q. Wang, B. T. Qiao, X. Y. Liu, X. F. Yang, X. D. Wang, J. X. Liang, J. Li, J. Y. Liu, T. Zhang, J. Am. Chem. Soc., 2013, 135, 15314-15317.

[6] M. Yang, J. L. Liu, S. Lee, B. Zugic, J. Huang, L. F. Allard, M. Flytzani-Stephanopoulos, J. Am. Chem. Soc., 2015, 137, 3470-3473.

[7] S. Yang, H. Lee, ACS Catal., 2013, 3, 437-443.

[8] S. Yang, J. Kim, Y. J. Tak, A. Soon, H. Lee, Angew. Chem., Int. Ed., 2016, 55, 2058-2062.

[9] H. S. Wei, X. Y. Liu, A. Q. Wang, L. L. Zhang, B. T. Qiao, X. F. Yang, Y. Q. Huang, S. Miao, J. Y. Liu, T. Zhang, Nat. Commun., 2014, 5, 5634.

[10] G. Vile, D. Albani, M. Nachtegaal, Z. P. Chen, D. Dontsova, M. Antonietti, N. Lopez, J. Perez-Ramirez, Angew. Chem. Int. Ed., 2015, 54, 11265-11269.

[11] F. R. Lucci, M. D. Marcinkowski, E. C. H. Sykes, J. L. Liu, M. Yang, L. M. Flytzani-Stephanopoulos, F. Allard, Nat. Commun., 2015, 6, 8550.

[12] J. M. Thomas, Z. Saghi, P. L. Gai, Top. Catal, 2011, 54, 588-594.

[13] M. Flytzani-Stephanopoulos, B. C. Gates, Annu. Rev. Chem. Biomol,, 2012, 3, 545-574.

[14] M. Flytzani-Stephanopoulos, Acc. Chem. Res., 2014, 47, 783-792.

[15] Q. Fu, H. Saltsburg, M. Flytzani-Stephanopoulos, Science, 2003, 301, 935-938.

[16] Q. Fu, W. L. Deng, H. Saltsburg, M. Flytzani-Stephanopoulos, Appl. Catal. $B, 2005,56,57-68$.

[17] M. Yang, L. F. Allard, M. Flytzani-Stephanopoulos, J. Am. Chem. Soc., 2013, 135, 3768-3771.

[18] N. C. Cheng, M. Norouzi Banis, J. Liu, A. Riese, S. C. Mu, R. Y. Li, T. K.

\section{Graphical Abstract}

Chin. J. Catal., 2017, 38: 1508-1514 doi: 10.1016/S1872-2067(17)62903-6

Single atom catalyst by atomic layer deposition technique

Niancai Cheng, Xueliang (Andy) Sun *

University of Western Ontario, Canada; Fuzhou University, China

This review summarizes recent development of single atom catalyst synthesized by atomic layer deposition and explores future research directions and trends.
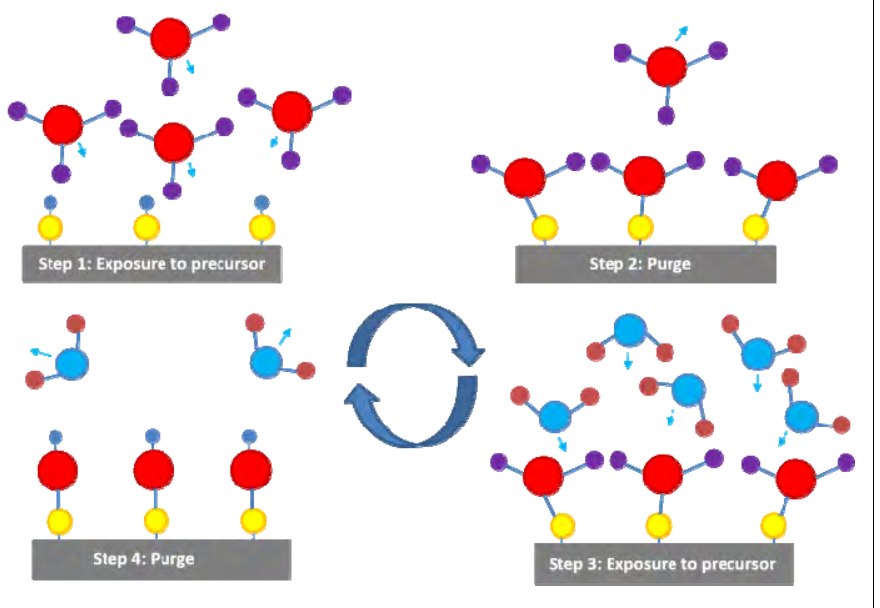
Sham, X. L. Sun, Energy Environ. Sci., 2015, 8, 1450-1455.

[19] N. C. Cheng, M. N. Banis, J. Liu, A. Riese, X. Li, R. Y. Li, S. Y. Ye, S. Knights, X. L. Sun, Adv. Mater, 2015, 27, 277-281.

[20] X. F. Zhang, J. J. Guo, P. F. Guan, C. J. Liu, H. Huang, F. H. Xue, X. L. Dong, S. J. Pennycook, M. F. Chisholm., Nat. Commun., 2013, 4, 2929.

[21] J. Liu, M. G. Jiao, L. L. Lu, H. M. Barkholtz, Y. P. Li, Y. Wang, L. H. Jiang, Z. J. Wu, D. J. Liu, L. Zhuang, C. Ma, J. Zeng, B. S. Zhang, D. S. Su, P. Song, W. Xing, W. L. Xu, Y. Wang, Z. Jiang, G. Q. Sun, Nat. Commun., 2017, 8, 15938.

[22] T. Ahn, J. H. Kim, H. M. Yang, J. W. Lee, J. D. Kim, J. Phys. Chem. C, 2012, 116, 6069-6076.

[23] S. Laurent, D. Forge, M. Port, A. Roch, C. Robic, L. V. Elst, R. N. Muller, Chem. Rev., 2008, 108, 2064-2110.

[24] A. H. Lu, E. L. Salabas, F. Schuth, Angew. Chem. Int. Ed., 2007, 46, 1222-1244.

[25] X. G. Li, W. T. Bi, C. Z. Wu, Y. Xie, L. Zhang, Q. Zhang, Y. Luo, S. Tao, W. S. Chu, Adv. Mater., 2016, 28, 2427-2431.

[26] L. L. Lin, W. Zhou, R. Gao, S. Y. Yao, X. Zhang, W. Q. Xu, S. J. Zheng, Z. Jiang, Q. L. Yu, Y. W. Li, C. Shi, X. D. Wen, D. Ma, Nature, 2017, 544, 80-83.

[27] S. H. Wang, L. Shang, L. L. Li, Y. J. Yu, C. W. Chi, K. Wang, J. Zhang, R. Shi, H. Y. Shen, G. I. N. Waterhouse, S. J. Liu, J. Tian, T. R. Zhang, H. Y. Liu, Adv. Mater., 2016, 28, 8379-8387.

[28] P. Q. Yin, T. Yao, Y. N. Wu, L. R. Zheng, Y. Lin, W. Liu, H. X. Ju, J. F. Zhu, X. Hong, Z. X. Deng, G. Zhou, S. Q. Wei, Y. D. Li, Angew. Chem. Int. Ed., 2016, 55, 10800-10805.

[29] U. Heiz, A. Sanchez, S. Abbet, W. D. Schneider, J. Am. Chem. Soc., 1999, 121, 3214-3217.

[30] S. Vajda, M. G. White, ACS Catal., 2015, 5, 7152-7176.

[31] S. H. Sun, G. X. Zhang, N. Gauquelin, N. Chen, J. G. Zhou, S. L. Yang, W. F. Chen, X. B. Meng, D. S. Geng, M. N. Banis, R. Y. Li, S. Y. Ye, S. Knights, G. A. Botton, T. K. Sham, X. L. Sun, Sci. Rep., 2013, 3, 1775.

[32] N. Cheng, S. Stambula, D. Wang, M. N. Banis, J. Liu, A. Riese, B. Xiao, R. Li, T. K. Sham, L. M. Liu, G. A. Botton, X. Sun, Nat. Commun., 2016, 7, 13638.
[33] S. M. George, Chem. Rev., 2010, 110, 111-131.

[34] J. Liu, X. Sun, Nanotechnology, 2015, 26, 024001.

[35] B. J. O’Neill, D. H. K. Jackson, J. Lee, C. Canlas, P. C. Stair, C. L. Marshall, J. W. Elam, T. F. Kuech, J. A. Dumesic, G. W. Huber, ACS Catal,, 2015, 5, 1804-1825.

[36] J. Hamalainen, M. Ritala, M. Leskela, Chem. Mater., 2014, 26, 786-801.

[37] J. L. Lu, J. W. Elam, P. C. Stair, Acc. Chem. Res., 2013, 46, 1806-1815.

[38] N. C. Cheng, Y. Y. Shao, J. Liu, X. L. Sun, Nano. Energy, 2016, 29, 220-242.

[39] H. Kim, H. B. R. Lee, W. J. Maeng, Thin Solid Films, 2009, 517 , 2563-2580.

[40] W. Setthapun, W. D. Williams, S. M. Kim, H. Feng, J. W. Elam, F. A. Rabuffetti, K. R. Poeppelmeier, P. C. Stair, E. A. Stach, F. H. Ribeiro, J. T. Miller, C. L. Marshall, J. Phys. Chem. C, 2010, 114, 9758-9771.

[41] J. W. Clancey, A. S. Cavanagh, R. S. Kukreja, A. Kongkanand, S. M. George, J. Vac. Sci. Technol. A, 2015, 33, 01A13011-01A13019.

[42] R. Subbaraman, D. Tripkovic, D. Strmcnik, K. C. Chang, M. Uchimura, A. P. Paulikas, V. Stamenkovic, N. M. Markovic, Science, 2011, 334, 1256-1260.

[43] H. J. Yin, S. L. Zhao, K. Zhao, A. Muqsit, H. J. Tang, L. Chang, H. J. Zhao, Y. Gao, Z. Y. Tang, Nat. Commun., 2015, 6, 6430.

[44] H. L. Fei, J. C. Dong, M. J. Arellano-Jimenez, G. Ye, N. Dong Kim, E. L. G. Samuel, Z. Peng, Z. Zhu, F. Qin, J. Bao, M. J. Yacaman, P. M. Ajayan, D. Chen, J. M. Tour, Nat. Commun., 2015, 6, 8668.

[45] I. E. L. Stephens, I. Chorkendorff, Angew. Chem. Int. Ed., 2011, 50, 1476-1477.

[46] H. Yan, H. Cheng, H. Yi, Y. Lin, T. Yao, C. L. Wang, J. J. Li, S. Q. Wei, J. L. Lu, J. Am. Chem. Soc., 2015, 137, 10484-10487.

[47] C. L. Wang, X. K. Gu, H. Yan, Y. Lin, J. J. Li, D. D. Liu, W. X. Li, J. Lu, ACS Catal., 2017, 7, 887-891.

[48] M. Piernavieja-Hermida, Z. Lu, A. White, K. B. Low, T. Wu, J. W. Elam, Z. Wu, Y. Lei, Nanoscale, 2016, 8, 15348-15356.

\section{原子层沉积技术制备单原子催化剂 \\ Niancai Cheng ${ }^{\text {a,b }}$, Xueliang (Andy) Sun ${ }^{\text {a,* }}$ \\ a西安大略大学机械材料工程系, 加拿大 \\ b 福州大学材料科学与工程学院, 福建福州350108, 中国}

摘要: 贵金属单原子催化剂因具有独特的催化性能和高的利用率而迅速引人关注. 原子层沉积(ALD)逐渐成为大批量合 成稳定单原子的有力工具. 本文总结了采用ALD合成单原子的最新进展, 以及未来的研究方向和趋势.

关键词: 单原子; 原子层沉积; 催化; 贵金属催化剂; 机理

收稿日期: 2017-07-06. 接受日期: 2017-08-14. 出版日期: 2017-09-05.

*通讯联系人. 电子信箱: xsun@eng.uwo.ca

本文的英文电子版由Elsevier出版社在ScienceDirect上出版(http://www.sciencedirect.com/science/journal/18722067). 